\title{
QANE AFI

\section{Examining the Impact of Double Time Written Tests in Nursing Education: A Mixed Methods Study}

Nadine M. Janes

University of Toronto, nadine.janes@utoronto.ca

Lesley Stoltz

Humber College, lesley.stoltz@humber.ca

Sue McCarthy

Humber College, Sue.McCarthy@humber.ca

Shahrzad Janani

Humber College, Shahrzad.Janani@humber.ca

Follow this and additional works at: https://qane-afi.casn.ca/journal

Part of the Other Nursing Commons

\section{Recommended Citation}

Janes, Nadine M.; Stoltz, Lesley; McCarthy, Sue; and Janani, Shahrzad (2022) "Examining the Impact of Double Time Written Tests in Nursing Education: A Mixed Methods Study," Quality Advancement in Nursing Education - Avancées en formation infirmière: Vol. 8: Iss. 1, Article 8.

DOI: https://doi.org/10.17483/2368-6669.1301

This Article is brought to you for free and open access by Quality Advancement in Nursing Education - Avancées en formation infirmière. It has been accepted for inclusion in Quality Advancement in Nursing Education - Avancées en formation infirmière by an authorized editor of Quality Advancement in Nursing Education - Avancées en formation infirmière. 


\section{Examining the Impact of Double Time Written Tests in Nursing Education: A Mixed Methods Study}

\section{Cover Page Footnote}

We acknowledge the support of Jason Powell as the Senior Dean, Faculty of Health Sciences \& Wellness, the collaboration of Heba Baig as the Research Coordinator, and the efforts of all Bachelor of Nursing Professors at Humber College during the implementation of the double time initiative. Nous reconnaissons le soutien de Jason Powell, doyen principal de la Faculty of Health Sciences \& Wellness (Faculté des sciences de la santé et du bien-être), la collaboration de Heba Baig, coordonnatrice de la recherche et les efforts de toutes les professeures du programme de Baccalauréat en sciences infirmières du Humber College lors de la mise en œuvre de l'initiative de temps double. 
Competitive postsecondary health sciences programs, including nursing programs, place high demands on students. Nursing students carry the weight of a heavy academic workload across classroom, laboratory, and clinical settings, requiring the integration of large volumes of knowledge and technical skills, rigorous progression rules with high stakes evaluations, and behavioural requirements for effectively managing highly emotional clinical settings. Some of the stressors experienced reflect the inherent nature of nursing education as a competitive professional degree program leading to a career in which client safety and quality health care depend on graduates with high intellectual and emotional capacities. However, in the interest of student health and well-being, it is worthwhile to consider what, if any, stressors can be minimized or eliminated. Such efforts are in keeping with the Humber College Strategic Plan (2018-2023), which includes a focus on optimizing student success by embedding health and well-being into all aspects of campus culture. The study reported here resulted from consideration of norms related to in-person timed written tests, a source of nursing student anxiety noted in published literature, and how time might be contributing to modifiable student stress. It involved an exploration of the student experience of double time allocation for all in-person major written tests and examinations for all students across all years and pathways of the University of New Brunswick/Humber Collaborative Bachelor of Nursing Program (BN Program) at the Humber College site in Ontario, Canada.

\section{Background and Review of Related Literature}

Students in the BN Program at the Humber College site have expressed and demonstrated the impact stress has on various aspects of their learning. Faculty have experienced the growing number of students who require support to manage their stress and develop effective coping strategies to optimize their academic success. Literature suggests that Humber College's BN students are not unique in their experience of stress. International publications related to nursing education affirm the high level of stress among students (Belnavis, 2019; Chernomas \& Shapiro, 2013; Gibbons, 2010; He et al., 2018; Kinsella et al., 2020; Labrague et al., 2018; Mills et al., 2020; Turner \& McCarthy, 2017). Sources of this stress are varied and include factors related to students' personal circumstances (e.g., financial pressures, family responsibilities, limited free time), their academic life (e.g., workload, assignments), and the complexities of clinical learning (e.g., the interpersonal environment of the clinical setting; patient acuity, expectations, and needs). Three systematic reviews involving published literature as far back as 1979 and as recently as 2016 collectively support the specific aim of this study by affirming that tests are one of the many sources of stress associated with students' academic life (Labrague et al., 2017; McCarthy et al., 2018; Pulido-Martos et al., 2012).

The stress of written evaluations at Humber College has manifested in increasing numbers of BN students seeking support from Accessible Learning Services (ALS) for test anxiety. That support has led to growing numbers of students being granted extra time to write tests (e.g., 1.5 times the allocated duration) when a student's test anxiety was linked to a disability. Accommodating the disability through extra time to write tests has resulted in logistical challenges for the organization's Test Centre and its available test writing space. Students who are not eligible for extra time to write tests (i.e., students without a disability underpinning their test anxiety) have access to academic advising to explore the basis of their anxieties and options for enhanced coping. However, faculty and staff have experienced the perception of many students that their stress and at times academic failings on written tests are solely due to insufficient time to complete these evaluations. This perception, in our experience, has at times made it difficult to facilitate essential student reflection on their study habits, competence level, or overall fit with the BN Program. 
These experiences, coupled with the known adverse impact of test anxiety on learning, well-being, and the academic success of nursing students (Edelman \& Ficorelli, 2005; Gibson, 2014; Khalaila, 2015; Mills et al., 2020; Quinn \& Peters, 2017; Shapiro, 2014), led to a review of our norms related to written tests.

BN faculty have implemented several support strategies in response to student stress and written tests (i.e., test anxiety). Many provide practice test questions in class before evaluations, as well as one-on-one meetings with students after evaluations to review tests and plan for enhanced study and/or test-writing strategies. ALS has initiated student workshops related to the management of test anxiety to supplement the one-to-one counselling provided by consultants. Finally, a concerted effort has been made in the BN Program overall to diversify evaluations and ensure students are given the opportunity to demonstrate their competence through varied testing formats that attend to different learning styles (e.g., short answer and essay questions) in the interest of minimizing students' stress related to one format only (e.g., multiple choice questions). Though valuable, these strategies combined have not appeared to lead to a substantial reduction in student stress surrounding written tests overall, as observed by faculty or expressed by students.

Interventions to manage nursing student test anxiety have been studied, including guided reflection (Beggs et al., 2011), biofeedback-assisted relaxation training (Prato \& Yucha, 2013), and double testing (Parsons \& Teel, 2013). An integrative review by Brodersen (2017) revealed 19 interventions for test anxiety in undergraduate nursing students across 33 publications dated between 1973 and 2014. Interventions included music therapy, aromatherapy, crib sheets, hypnotherapy, counselling, guided imagery, pet therapy, and workshops on test-taking skills. Quinn and Peters (2017) conducted a systematic review exploring the results of seven studies between 2006 and 2015 related to nursing students' test anxiety. Environmental adjustments and student behaviour modifications effectively categorized the interventions identified to reduce anxiety. The former included diffusing essential lemon oil, playing classical music, and having a therapy dog present, while the latter included interventions such as biofeedback relaxation techniques and progressive muscle relaxation. The results of both reviews as expressed by the researchers highlight the need for more research to strengthen the evidentiary support for existing interventions and to introduce novel interventions designed to reduce nursing student test anxiety.

In summary, the literature to date affirms nursing students' experience of stress overall and that tests are a common source of that stress. Such stress has been linked to several negative outcomes related to student well-being and academic success. Finally, no one intervention has emerged as particularly effective in mitigating student stress related to written tests. In the absence of empirical guidance, we turned to our experiential knowledge in designing the study reported here. Student test anxiety remained a flourishing issue, despite strategies used by BN faculty to reduce student stress. A decision was therefore made to implement a strategy based on our anecdotal understanding of the student perspective. That is, many students had voiced their perception that a lack of time is a major source of their test anxiety and a key factor affecting their academic success. Hence, double time on all major in-person written tests and examinations emerged as the intervention of choice.

Extra time on written tests is a common accommodation for postsecondary students with disabilities (Zuriff, 2000). What is less common is the use of extra time for all students in the interest of reducing non-disability-related anxieties over evaluations. Only two studies were found related to the intervention. Both were focused on students in physical therapy programs and in relation to practical tests (Schwartz et al., 2015; Zhang et al., 2013). Zhang and colleagues (2013) 
described students' claims that time limits negatively impact their academic performance. However, their study demonstrated no significant difference between student performance on untimed and timed examinations. Regarding stress as an outcome, Schwartz and colleagues' study (2015) identified lower student anxiety when they completed a test in their preferred format (timed versus untimed) rather than the untimed format exclusively.

Because of the lack of evidential support for double time written tests as an intervention to mitigate nursing student stress, this exploratory study was designed with a focus on nursing student performance (test grades) and experience. The following research questions guided the study: (a) What is the experience of double time on all in-person written major tests from the perspective of BN students? (b) Is there a relationship between the time it takes a student to write a test and their grade on that evaluation measure when double time is provided for all students?

\section{Methods}

This study involved a mixed methods descriptive correlational design. Qualitative and quantitative data were collected to explore students' experiences of double time on all major inperson written tests, including exams, and to assess for any relationship between the time it takes a student to write a test and their grade on that evaluation measure. Regarding the latter, the aim was to describe relationships among the variables of time and grade rather than to infer cause and effect. Further, though double time was offered, students were given the option to submit their written test or exam before double time was reached. Results from this exploratory study may lead to more in-depth rigorous study of double time as an intervention for mitigating nursing student stress related to tests and the resultant impact on academic performance.

\section{Sample Selection}

Convenience sampling was used in this study. All 853 students enrolled in the BN Program at the time of the study across all three academic pathways (i.e., second-entry, regular, RPN-RN bridge) were invited to participate in the qualitative component of this study. Participation was voluntary and anonymous. Regarding the exploration of relationships between test time and grades, data from all students $(N=853)$ were automatically included in the sample as is consistent with continuous program evaluation efforts.

\section{Data Collection Techniques}

Raw data consisted of the following:

1. The length of time each student took to complete a test (in minutes). These data were collected by recording the times each student began and submitted a test. Times were recorded on an attendance form or similar document completed by test proctors.

2. The grade each student received on a test.

3. Students' perspectives related to the double time initiative. These data were solicited using an online survey developed by the research team (see Table 1).

During the 2018-2019 academic year, time and grade student-related data were collected from 16 fall term courses and 9 winter term courses. Clinical courses and elective courses were not included in the study. Across these 25 courses, there were 59 major in-person written tests and exams involving double time. To manage missing data, only students with both a grade and a time recorded for their respective test were included in the study. To assess for outliers, the data were audited for data entry problems. No data entry issues were noted. 


\section{Table 1}

Online Student Survey

$\begin{array}{ccc}\text { Please check your pathway and the semester/year you are completing in April 2019: } \\ \begin{array}{c}\square \text { Regular (4 year) } \\ \square \text { Second-entry }\end{array} \\ \square \text { Year 1 } \\ \square \text { Year 2 } & \square \text { Semester 3 } & \square \text { B Bridge } \\ \square \text { Year 3 } & \square \text { Semester 6 } & \square \text { Semester 8 (Year 4) } \\ \square \text { Year } 4 & \end{array}$

QUESTION 1: Did the double time on major tests and examinations have an impact on you? (check one below)

$\square$ Yes $\quad \square$ No (skip to question \#3) $\quad \square$ I am not sure (skip to question \#3)

QUESTION 2: If you answered "Yes" for Question 1, how would you describe the impact? (check one below)

$\begin{array}{lll}\square \text { It was positive } \square \text { It was negative } & \begin{array}{l}\square \text { It was neither } \\ \text { positive nor } \\ \text { negative }\end{array} & \begin{array}{l}\square \text { It was both positive and } \\ \text { negative }\end{array}\end{array}$

QUESTION 3: Please tell us more about your answer to Question 1. If the double time did not have an impact on you, describe briefly why not. If the double time did have an impact on you, describe the impact briefly including why you described it as positive, negative, both, or neither.

QUESTION 4: Should double time for all major tests and exams continue to be offered for all BN students?
$\square$ Yes
$\square$ No
I am not sure

\section{Recruitment Strategies}

Recruitment for student participation in the online survey had two steps. First, the associate dean of the BN Program posted an announcement on the Blackboard site, a learning management system, in which all BN students are enrolled. The announcement introduced the study and informed students that they would receive an email from the study Research Coordinator inviting them to volunteer to participate in the survey. The email invitation was sent to all BN students across all three pathways through their preferred email address. It included a link to the online survey. Consent to participate was implied when students completed and submitted the survey. The timing of the Blackboard announcement and email with survey link were scheduled to align with the end of the semester but before students departed for the summer vacation. Second, three reminder emails were sent by the research coordinator to maximize student engagement in the survey. 


\section{Managing and Recording Data}

Course faculty submitted data related to the time students took to write a test and their grade on that test to the research coordinator for the project. The research coordinator recorded all data on an excel spreadsheet, including student identifiers (name, student number). The research coordinator conducted an analysis of the data in aggregate format with no student identifiers. After the research coordinator completed the analysis, all spreadsheets and forms revealing student identification were deleted from her computer.

The research coordinator collected online survey data. The survey was anonymous in that no identifiers other than program pathway and year/semester of the program were included. The research coordinator stored the survey results in a password protected computer folder accessible to the research team for analysis.

\section{Data Analysis Techniques}

Descriptions of the students' experiences of double time as recorded on the survey were analyzed for themes. Each member of the research team read descriptions independently. Descriptions were grouped into categories according to the similarity of the experiences described and given a category name. Team members met as a group to share their categories and the data within each category. Through a process of consensus building over four face-to-face meetings and remote online communications, the team agreed on one taxonomy of categories to represent data related to the student experience of the double time initiative.

Descriptive statistics for all study variables included means, standard deviations, and ranges. Student data were divided by course, semester, and test name. Within each test, student data were further divided into two groups: group 1 completed the test in the regular time allotted for the test or less; group 2 took more than the regular time allotted for the test, up to the full double time available. Average grades and standard deviations within each of these two groups were computed, as were independent-samples $t$-tests to determine whether there was a significant difference in grades between the groups. Finally, Pearson correlations were computed to determine whether there was a significant relationship between the two values of time and grade, looking at the performance of the entire group of students as a whole writing each test. The strength of correlations was determined using the following standards: very weak $=.00$ to .19 ; weak $=.20$ to .39 ; moderate $=.40$ to $.59 ;$ strong $=.60$ to .79 ; very strong $=.80$ to 1.0 . An alpha level of $\leq .05$ was used to determine significance levels for all analyses.

\section{Trustworthiness}

Three strategies were implemented to ensure the findings (i.e., themes) from the survey stayed true to the descriptions given by student participants rather than reflecting any potential bias of the research team overall or of individual members of the research team specifically. First, before the study began, each member of the research team wrote a one-page reflection on their anticipations related to the study and what they presumed the findings would reveal. These reflections were used during the analysis process by individuals and the overall team as a check and balance. That is, if the emerging themes directly reflected what a team member recorded as their anticipated findings, a re-examination of the data and review of the thematic analysis was initiated to explore for any misrepresentations of data. The process of consensus building that was used to agree on the final themes to represent the survey data was a second strategy to protect the credibility of the findings. 
Finally, each theme representing the student experience intentionally includes data that are representative of the majority of students' experiences (i.e., $>50 \%$ of respondents). This ensures findings reflect patterned and common experiences rather than exceptional or outlying experiences. The percentages of students who experienced a particular theme are provided in the findings section of this report as a transparent audit trail of analytic decisions for the reader.

\section{Ethics}

The study proposal was submitted to the Humber College Research Ethics Board (REB) for risk assessment. It was determined that the study complies with the provision of the Tri-Council Policy Statement (TCPS2) and was exempt from the requirements of research ethics review:

Article 2.5: Quality assurance and quality improvement studies, program evaluation activities, and performance reviews, or testing within normal educational requirements when used exclusively for assessment, management or improvement purposes, do not constitute research for the purposes of this Policy, and do not fall within the scope of REB review. (Canadian Institutes of Health Research et al., 2014)

\section{Findings}

A total of 457 students responded to the online survey in its entirety or partially, representing a response rate of 54\% (457/853). The percentages of respondents by program pathway are similarly proportionate to the number of students enrolled in each pathway: $67 \%$ were regular four-year students, $21 \%$ were second-entry students, and $16 \%$ were RPN-RN bridge students. As stated previously, data related to students' test performance (i.e., time and grade) were collected for all 853 students.

\section{The Student Experience of Double Time Tests}

Of the students who responded to the online survey, $415(91 \%)$ experienced the option to take up to double the allotted time to complete a written test as impactful, while $33(7 \%)$ denied any impact, and $8(2 \%)$ were uncertain if they experienced an impact. Table 2 provides a breakdown of how the 415 students who affirmed an impact from the double time defined the nature of the impact. Finally, 407/430 (94.65\%) students responded yes when asked if double time for all major written tests should continue to be offered for all BN students. In contrast, $9(2.09 \%)$ students indicated the double time should not continue, and $14(3.26 \%)$ were unsure.

\section{Table 2}

Nature of Impact of Double Time

\begin{tabular}{lcc}
\multicolumn{1}{c}{ Impact of Double time } & Responses (\%) & Responses (no.) \\
\hline It was positive & 94.7 & 393 \\
It was negative & 0.48 & 2 \\
It was neither positive nor negative & 0.24 & 1 \\
It was both positive and negative & 4.58 & 19 \\
\hline & TOTAL & 415 \\
\hline
\end{tabular}


Narrative responses to the third question on the survey $(N=430)$ provided qualifying details related to students' responses about double time impact. Specifically, participants described in detail what they experienced on an individual level that they classified as impactful or why they experienced no impact in relation to the double time initiative. From the perspective of most study participants, the impact of the double time initiative can be captured by two themes: Calming $(N$ $=280 ; 65 \%)$ and Enabling $(N=360 ; 84 \%)$.

\section{Calming Impact of Double Time}

The theme of Calming reflects the impact of double time on students' emotional state or psychological functioning. Students provided descriptive accounts of a decrease in emotions such as "stress," "panic," or "worry" and/or an increase in more healthful emotions such as "comfort," "peace of mind," and "confidence." Even some who did not take advantage of the double time to write tests experienced these emotional benefits: "Although I didn't really find myself needing the extra time, it made me feel more relaxed during the exam, as I didn't feel the need to rush and constantly check the time." Similarly, "I was able to complete the exams well within the time limit. I suppose it was at least a bit calming that I had so much time to work with if I felt I needed it."

For those who did take advantage of the double time, the Calming impact was often described in relation to managing anxiety in particular, whether the anxiety was explicitly linked to a disability or not:

I felt that it allowed me to not feel as stressed and anxious being worried while watching the clock. I used to find myself calculating my remaining time several times throughout my tests and exams and this semester I felt more at ease and gave me more confidence to think and answer my questions effectively.

The double time gave many students the time to implement calming strategies to manage their anxiety and mitigate its deleterious influence, as described by the following two students:

I become very anxious when writing exams to the point where it takes a toll on my physical health. I always have stomach pain and nausea, headaches, and tremble. When sitting down for the exams it always takes me some time to gather myself and calm my nerves enough to clear my head to write the exam. For all of my exams I felt that I needed the double time to alleviate my anxiety.

Exam periods often come with stressful feelings, and students may develop anxiety along with the exam stress. The double time gives room for such students to reorganize their level of emotion and refocus on the examination.

One respondent provided a unique link between their experience of "calmness" and the sense of normalcy the double time afforded them as a person with a disability:

The double time also made me feel included. I was able to write my exam in a class setting with my peers and my professor present instead of going to the test center where I felt excluded and unable to ask my professor for assistance if I needed it. Writing in the test center because of my extra time was unfamiliar to me. I felt a sense of calmness having the double time and familiarity writing with my peers and professor close by. Having the double time helped me immensely. 
Similarly,

The double time allowed me to write my tests with the class, offering me a sense of normalcy. I no longer needed to write separately from my peers.

As a final note, some respondents described more of an indirect Calming impact of the double time initiative, such as the student who benefited indirectly through their peers: "It also made my friends sitting next to me stress less, which then allowed me to feel more calm."

\section{Enabling Impact of Double Time}

The theme of Enabling captured students' experiences with double time in relation to its impact on cognitive functioning, test-taking abilities, or academic standing: "time for our brain to work efficiently." Coded within this theme were descriptive accounts that relate more to test performance than to a student's emotional/psychological state as per the Calming theme: "Double time helped me to utilize all cognitive abilities which I might not be able [to] apply in the rush situation of single time." Similarly, "the extra time allowed for clearer organization of thought and more accurate assessment of knowledge in the brain transferring to the paper."

From the students' perspective, the initiative provided the time to "make solid, rational decisions"; "reread and process the question"; "take my time in organizing and collecting my knowledge about the questions"; "think deeply in the questions and answer carefully"; and "think over the questions, weigh all possible answers and settle with the best possible answer." Many students labelled these processes as thinking "critically."

Students equated the opportunity for enhanced thinking processes without the "distraction of time" as an opportunity to better demonstrate their knowledge, or as one respondent described, "to complete my tests and exams to the best of my ability." The two responses below exemplify this perspective that double time enhances the meaning of student grades on tests and provides a better indication of student learning:

The double time had a positive impact in me as it allowed me to take my time, and clearly think my way through each question or scenario, instead of speeding through it, working off of my memory alone. There's no point in memorizing an answer to a test question if it is to be forgotten immediately after the test, it's better if the concept is understood.

It allows students to take the time necessary during the exam to really think critically about the questions rather than rushing to beat the clock. With this, it helps make testing a challenge of our thinking rather than a challenge of facing the time.

In addition to Enabling a demonstration of a student's best abilities through more effective and critical thinking processes, the double time simply allowed students to "cross-check" their work: "Having the time to review my exam, made me find mistakes I wouldn't have found if I didn't have the extra time to review." The perceived outcome for some were better grades overall:

The double time had a positive effect on me as it eliminated the impact time had on my testing abilities. The time constraint was no longer an issue that I had, and it allowed me to take my time with each question to fully understand what it was asking of me, and well it gave me extra time to look over my work that I would have not been able to do without the double time. I have seen an increase in my grades since beginning to receive the double time. 
A number of respondents chose to qualify the Enabling impact by highlighting the need for double time with particular types of questions: "Challenging questions need more time for consideration of all applicable factors." The student below clearly differentiated the contextual value of double time in relation to particular types of test questions:

I believe that the double time allowance was beneficial however, only for acute health challenges [a particular course] - as it required us to fill out short answer questions. Otherwise, for the rest of my courses I finished way before the end time. MC [multiple choice] usually does not require that much time[;] however, short answers and dosage calculations certainly do!

As a final note, the Enabling impact may not be universally experienced. At the least, it may be experienced more explicitly by certain students, including those with English as an additional language or those with a disability: "I feel like it's a fair implementation for those who truly need it and struggle a lot without having to get double time through the learning center." Consider the following assertions of two different respondents:

I am an immigrant to the country and have some trouble with English. [It] takes me longer to read and understand the meaning of sentences but they are not true reflection of my capabilities as a student. I believe that I did well because I had enough time to go over my exam.

English is not my first language, so it is very helpful to have time to read the questions slowly in order to understand them properly. This is a way to make it fair for all students.

\section{Time and Grade Relationship}

Only statistically significant results are included in Tables 3 and 4. They detail descriptive statistics, as well as the results of $t$-tests and correlational analyses. As described earlier, the research question that guided these analyses was as follows: Is there a relationship between the time it takes a student to write a test and their grade on that evaluation measure when double time is provided for all students?

Data from the independent-samples $t$-tests revealed there were some statistically significant differences in average grades among students who completed their test/exam within regular time, compared to those who completed their test/exam in double time. Of note, all these differences were considered small and largely in favour of those writing within regular time. Specifically, students in four fall courses who wrote within regular time, achieved grades significantly higher (3.1\% to $8.2 \%$ ) than those who wrote in double time (see Table 3). In the winter term, differences in students' grades were again statistically significant in five courses, with those writing within regular time $0.2 \%$ to $4.8 \%$ higher than those who wrote in double time (see Table 4 ). In one winter course, the difference between students' grades was statistically significant, but both groups achieved the same rounded mean (see Table 4).

Pearson correlations revealed a statistically significant relationship between overall time and grade in 11 major tests/exams across 7 courses in the fall term (see Table 3) and 6 tests/exams across 5 courses in the winter term (see Table 4). All statistically significant relationships in the fall were negative, indicating that the longer a student took to complete their test, the lower their grade was. In the winter term, in all but two tests, as time to write increased, student grades decreased (see Table 4). Finally, in all but one of the aforementioned evaluations, the statistically significant relationships identified were very weak to weak. 


\section{Table 3}

Statistically Significant Independent-Samples t-Test Results for Regular Time Versus Double Time Bachelor of Nursing Students and Pearson Correlations for all Bachelor of Nursing Students, Fall 2018

\begin{tabular}{|c|c|c|c|c|c|c|c|}
\hline \multirow[b]{2}{*}{$\begin{array}{c}\text { Course } \\
\text { (test/exam) }\end{array}$} & \multirow[b]{2}{*}{$\begin{array}{l}\text { Program } \\
\text { pathway }\end{array}$} & \multicolumn{4}{|c|}{ t-Test } & \multicolumn{2}{|r|}{ Correlation } \\
\hline & & $\begin{array}{l}\text { N } \\
\text { (allotted time in } \\
\text { minutes) }\end{array}$ & $\begin{array}{c}\text { Percentage } \\
\text { grade } \\
M(S D)\end{array}$ & $t$-value & $d f$ & $N$ & $\begin{array}{c}r \\
\text { time and grade } \\
\text { (RT \& DT combined) }\end{array}$ \\
\hline & & & Midterms & & & & \\
\hline $\begin{array}{l}\text { Anatomy \& } \\
\text { Physiology } 1 \text { (T1) }\end{array}$ & $\mathrm{R}$ & $\begin{array}{l}82(\mathrm{RT}=0-75) \\
103(\mathrm{DT}=76-150)\end{array}$ & $\begin{array}{l}80.1(11.3) \\
71.9(15.2)\end{array}$ & $4.24 * *$ & 183 & 185 & $-.37 * *$ \\
\hline $\begin{array}{l}\text { Anatomy \& } \\
\text { Physiology } 1 \text { (T2) }\end{array}$ & $\mathrm{R}$ & $\begin{array}{l}101(\mathrm{RT}=0-75) \\
71(\mathrm{DT}=76-150)\end{array}$ & $\begin{array}{l}83.8(11.1) \\
76.8(17.3)\end{array}$ & $3.01 * *$ & 170 & 172 & $-.27 * *$ \\
\hline $\begin{array}{l}\text { Professional } \\
\text { Relationships (E) }\end{array}$ & $\mathrm{R}$ & $\begin{array}{l}80(\mathrm{RT}=0-60) \\
88(\mathrm{DT}=61-120)\end{array}$ & $\begin{array}{l}83.9(8.9) \\
76.7(11.1)\end{array}$ & $4.57 * *$ & 166 & 168 & $-.46 * *$ \\
\hline $\begin{array}{l}\text { Pathophysiology } 1 \\
\text { (T1) }\end{array}$ & $\mathrm{R}, \mathrm{SP}$ & $\begin{array}{l}99(\mathrm{RT}=0-80) \\
94(\mathrm{DT}=81-160)\end{array}$ & $\begin{array}{l}83.8(9.7) \\
79.6(10.2)\end{array}$ & 2.89 & 191 & 193 & $-.14 *$ \\
\hline $\begin{array}{l}\text { Health Assessment } \\
\text { (E) }\end{array}$ & $\mathrm{R}$ & $\begin{array}{l}91(\mathrm{RT}=0-90) \\
54(\mathrm{DT}=91-180)\end{array}$ & $\begin{array}{l}70.1(7.6) \\
68.5(8.8)\end{array}$ & 1.72 & 143 & 145 & $-.22 * *$ \\
\hline $\begin{array}{l}\text { Pharmaco- } \\
\text { therapeutics (E) }\end{array}$ & $\mathrm{R}$ & $\begin{array}{l}94(\mathrm{RT}=0-110) \\
28(\mathrm{DT}=111-220)\end{array}$ & $\begin{array}{l}61.4(11.7) \\
56.1(13.0)\end{array}$ & $2.05 *$ & 120 & 122 & -.15 \\
\hline $\begin{array}{l}\text { Health Assessment } \\
\text { (E) }\end{array}$ & $\mathrm{S}$ & $\begin{array}{l}45(\mathrm{RT}=0-90) \\
18(\mathrm{DT}=91-180)\end{array}$ & $\begin{array}{l}81.1(5.8) \\
76.9(7.5)\end{array}$ & $2.35 *$ & 61 & 63 & -.11 \\
\hline $\begin{array}{l}\text { Anatomy \& } \\
\text { Physiology } 1(\mathrm{E})\end{array}$ & $\mathrm{R}$ & $\begin{array}{l}75(\mathrm{RT}=0-120) \\
94(\mathrm{DT}=121-240)\end{array}$ & $\begin{array}{l}81.2(13.6) \\
75.9(12.3)\end{array}$ & $2.62 *$ & 167 & 169 & $-.20 * *$ \\
\hline
\end{tabular}




\begin{tabular}{|c|c|c|c|c|c|c|c|}
\hline $\begin{array}{l}\text { Nursing as a } \\
\text { Profession (E) }\end{array}$ & $\mathrm{R}$ & $\begin{array}{l}67(\mathrm{RT}=0-110) \\
91(\mathrm{DT}=111-220)\end{array}$ & $\begin{array}{l}72.7(11.1) \\
69.5(10.7)\end{array}$ & 1.86 & 156 & 158 & $-.17 *$ \\
\hline $\begin{array}{l}\text { Professional } \\
\text { Relationships (E) }\end{array}$ & $\mathrm{R}$ & $\begin{array}{l}106(\mathrm{RT}=0-80) \\
47(\mathrm{DT}=81-160)\end{array}$ & $\begin{array}{l}81.4(8.0) \\
78.3(9.2)\end{array}$ & $2.05 *$ & 151 & 153 & $-.23 * *$ \\
\hline $\begin{array}{l}\text { Pathophysiology } 1 \\
\text { (E) }\end{array}$ & $\mathrm{R}, \mathrm{SP}$ & $\begin{array}{l}54(\mathrm{RT}=0-120) \\
90(\mathrm{DT}=121-240)\end{array}$ & $\begin{array}{l}77.6(13.9) \\
78.2(12.4)\end{array}$ & -.24 & 142 & 144 & $-.18 *$ \\
\hline $\begin{array}{l}\text { Young Families' } \\
\text { Health (E) }\end{array}$ & $\mathrm{R}$ & $\begin{array}{l}29(\mathrm{RT}=0-100) \\
81(\mathrm{DT}=101-200)\end{array}$ & $\begin{array}{l}66.1(6.1) \\
63.6(8.2)\end{array}$ & 1.50 & 108 & 110 & $-.21 *$ \\
\hline $\begin{array}{l}\text { Community \& } \\
\text { Population Health } \\
\text { Nursing (E) }\end{array}$ & $\mathrm{R} / \mathrm{B}$ & $\begin{array}{l}63(\mathrm{RT}=0-90) \\
147(\mathrm{DT}=91-180)\end{array}$ & $\begin{array}{l}71.9(7.6) \\
69.8(8.6)\end{array}$ & 1.67 & 208 & 210 & $-.16^{*}$ \\
\hline
\end{tabular}

Note. $\mathrm{T} 1=$ Test $1 ; \mathrm{T} 2=$ Test $2 ; \mathrm{E}=$ exam; $\mathrm{R}=$ regular; $\mathrm{S}=$ second-entry; $\mathrm{SP}=$ second-entry preparatory semester; $\mathrm{B}=\mathrm{RPN}-\mathrm{RN}$ bridge; $N=$ sample size; RT = regular time; DT = double time; $M=$ mean; $S D=$ standard deviation; $d f=$ degrees of freedom; $r=$ correlation.

$* p \leq .05 . * * p \leq .001$.

\section{Table 4}

Statistically Significant Independent-Samples t-Test Results for Regular Time Versus Double Time Bachelor of Nursing Students and Pearson Correlations for all Bachelor of Nursing Students, Winter 2019

\begin{tabular}{|c|c|c|c|c|c|c|c|}
\hline \multirow[b]{2}{*}{$\begin{array}{c}\text { Course } \\
\text { (test/exam) }\end{array}$} & \multirow[b]{2}{*}{$\begin{array}{l}\text { Program } \\
\text { pathway }\end{array}$} & \multicolumn{5}{|c|}{ T-test } & \multirow{2}{*}{$\begin{array}{c}\text { Correlation } \\
r \\
\text { time and grade } \\
\text { (RT \& DT } \\
\text { combined) }\end{array}$} \\
\hline & & $\begin{array}{l}\quad N \\
\text { (allotted time in } \\
\text { minutes) }\end{array}$ & $\begin{array}{c}\text { Percentage } \\
\text { grade } \\
M(S D)\end{array}$ & $t$-value & $d f$ & $N$ & \\
\hline \multicolumn{8}{|c|}{ Midterms } \\
\hline Nursing \& Wellness (E) & $\mathrm{R}$ & $\begin{array}{l}74(\mathrm{RT}=0-80) \\
89(\mathrm{DT}=81-160)\end{array}$ & $\begin{array}{l}75.2(8.8) \\
74.2(9.7)\end{array}$ & $.70 *$ & 161 & 163 & -.08 \\
\hline
\end{tabular}




\begin{tabular}{|c|c|c|c|c|c|c|c|}
\hline $\begin{array}{l}\text { Introduction to Nursing } \\
\& \text { Health (E) }\end{array}$ & $S$ & $\begin{array}{l}16(\mathrm{RT}=0-90) \\
54(\mathrm{DT}=91-180)\end{array}$ & $\begin{array}{l}74.1(7.2) \\
73.9(8.1)\end{array}$ & $.10^{*}$ & 68 & 70 & -.22 \\
\hline $\begin{array}{l}\text { Anatomy \& Physiology } \\
2 \text { (T1) }\end{array}$ & $\mathrm{R}$ & $\begin{array}{l}65(\mathrm{RT}=0-75) \\
87(\mathrm{DT}=76-150)\end{array}$ & $\begin{array}{l}81.6(11.4) \\
77.7(11.6)\end{array}$ & $2.10 *$ & 150 & 152 & $.24 *$ \\
\hline $\begin{array}{l}\text { Enhanced Well Being } \\
\text { in Situations of } \\
\text { Chronicity (E) }\end{array}$ & $S$ & $\begin{array}{l}24(\mathrm{RT}=0-90) \\
46(\mathrm{DT}=91-180)\end{array}$ & $\begin{array}{l}81.0(7.0) \\
81.0(7.0)\end{array}$ & $.01 *$ & 68 & 70 & -.15 \\
\hline Pathophysiology 2 (T1) & $\mathrm{R} / \mathrm{B}$ & $\begin{array}{l}145(\mathrm{RT}=0-90) \\
54(\mathrm{DT}=91-180)\end{array}$ & $\begin{array}{l}80.9(8.5) \\
76.1(10.7)\end{array}$ & $3.23^{*}$ & 197 & 199 & $-.21 *$ \\
\hline $\begin{array}{l}\text { Chronic Health } \\
\text { Challenges (E) }\end{array}$ & $\mathrm{R}$ & $\begin{array}{l}67(\mathrm{RT}=0-90) \\
77(\mathrm{DT}=91-180)\end{array}$ & $\begin{array}{l}75.0(8.7) \\
70.9(8.4)\end{array}$ & $2.90 *$ & 142 & 144 & $-.24 *$ \\
\hline $\begin{array}{l}\text { Bridging } \\
\text { Pathophysiology (T2) }\end{array}$ & B & $\begin{array}{l}15(\mathrm{RT}=0-60) \\
35(\mathrm{DT}=61-120)\end{array}$ & $\begin{array}{l}74.5(12.7) \\
81.3(8.7)\end{array}$ & -1.89 & 48 & 50 & $.29 *$ \\
\hline $\begin{array}{l}\text { Acute Health } \\
\text { Challenges (T1) }\end{array}$ & $\mathrm{R} / \mathrm{B} / \mathrm{S}$ & $\begin{array}{l}6(\mathrm{RT}=0-90) \\
245(\mathrm{DT}=91-180)\end{array}$ & $\begin{array}{l}75.5(9.3) \\
68.0(10.3)\end{array}$ & 1.76 & 249 & 251 & $-.13 *$ \\
\hline Pathophysiology 2 (E) & $\mathrm{R} / \mathrm{B}$ & $\begin{array}{l}60(\mathrm{RT}=0-120) \\
131(\mathrm{DT}=121-240)\end{array}$ & $\begin{array}{l}77.2(12.4) \\
73.8(12.1)\end{array}$ & 1.78 & 189 & 191 & $-.21 *$ \\
\hline
\end{tabular}

Note. $\mathrm{T} 1$ = Test $1 ; \mathrm{T} 2=$ Test $2 ; \mathrm{E}=$ exam; $\mathrm{R}=$ regular; $\mathrm{S}=$ second-entry; $\mathrm{B}=\mathrm{RPN}-\mathrm{RN}$ bridge; $N=$ sample size; $\mathrm{RT}=$ regular time; $\mathrm{DT}$ $=$ double time; $M=$ mean; $S D=$ standard deviation; $d f=$ degrees of freedom; $r=$ correlation.

${ }^{*} p \leq .05$. 


\section{Discussion}

Our aim was to explore how the factor of time might be contributing to modifiable student stress. Our underlying interest was enhancing student well-being. Study findings suggest that double time may alter the experience of writing a test. It mitigated student participants' stress and optimized their emotional and psychological well-being, as well as their cognitive capacity. Despite these positive experiential impacts, few positive relationships were identified between the time a student took to write a test and their grade on the evaluation measure. The few relationships that emerged between time and grades, albeit largely weak in nature, demonstrated mostly a negative relationship; the longer a student took to write a test, the lower their grade. As well, of the significant differences in grades among students who wrote in regular time versus double time, the differences were relatively small but were largely in favour of those writing within regular time.

These results appear contrary to the perspective of some Humber College BN students referred to earlier who felt that test performance is solely related to the time available to write the test. A grounded theory study by Bonaccio and Reeve (2010) may explain this student perspective to some degree. Through an exploration of undergraduate students' perceptions of the sources of test anxiety, students' tendency to look for external causes for their stress (e.g., test content or format) rather than focusing on self-related characteristics (e.g., lack of ability, lack of preparation) was revealed. Bonaccio and Reeve linked this pattern to the self-worth model of test anxiety, which suggests it is less threatening to a test taker's self-worth to focus on the test's characteristics as a source of anxiety than it would be to focus on their own purported weaknesses.

The double time initiative required flexibility on the part of faculty, who were required to proctor exams at different scheduled times (e.g., evenings) and for longer lengths of time than normal. Operational challenges also arose during the scheduling process in relation to finding appropriately sized testing rooms available for long periods of time to accommodate the double timing. Given that double time did mitigate stress from the student perspective, did not largely relate to student performance in terms of grades, and did result in some logistical challenges, the question remains, should double time replace past norms related to timed written tests? After all, student participants overwhelmingly supported its continuation.

Divergent views surrounding standard allotments of time for written tests are not new in our experience as nurse educators. Calculating the "right" number of minutes to allot for test questions is often embedded in tradition and varied learning expectations within academic settings. While some feel a standard time per question on a written test is essential, others suggest the achievement of the learning outcomes associated with a written test is not contingent upon a rigid time limit. To ease this tension, the utility of a pragmatic approach is valuable. The purpose of such an approach is not to conclude that one argument is true/good and one false/bad, but to look beyond this tension and shift our focus to the practical consequences or endpoints of our quandary (Warms \& Schroeder, 1999). The question that then served to guide our pragmatic reflection in this discussion was as follows: What difference would it make if nursing students were allotted double time for all in-person major written tests/exams? In terms of outcomes, we considered the differences double time might make to students' mental well-being, to the effectiveness of the learning environment, and to students' practice after graduation.

Increases in the severity and extent of mental health problems among postsecondary students, including nursing students, are a growing concern (Chernomas \& Shapiro, 2013; Mills 
et al., 2020; Myrick \& Pepin, 2019). Pascoe and colleagues (2020) conducted a narrative review of research concerning the impact of academic-related stress on the psychological and emotional well-being of students, including those in higher education. They found research to support that ongoing academic-related stress from test taking and fear of poor grades can contribute to mental health challenges such as depression, anxiety, and substance use, in addition to sleep disturbances, increased dropout rates from burnout and low motivation, and poor academic outcomes. Double time might contribute to a shift in the stressful experience of writing tests and exams for nursing students to one that includes positive feelings of calm and enablement, thereby making an ultimate difference to students' mental well-being.

Several studies have examined the conditions required for learning effectiveness within nursing education programs (Duff, 2016; Lethbridge, 2010; Moore \& Ward, 2017; Siu et al., 2005). Empowering conditions within classroom learning environments include opportunities to learn and develop, as well as access to the information, support, and resources required to learn in meaningful ways (Lethbridge, 2010; Siu et al., 2005). Micro-examination of resources specifically has included an assessment of students' perceived access to the time available to accomplish learning goals (Lethbridge, 2010; Siu et al., 2005). Accordingly, there is conceptual and psychometric evidence to suggest that time has been considered an important indicator of nursing students' resource-related structural empowerment within the classroom. Double time might contribute to the empowering nature of nursing education for students.

The effectiveness of the learning environment for nursing students has also been examined in relation to the interpersonal approaches of faculty. Faculty behaviors that may best minimize student stress and maximize their learning have been described as caring, respectful, inviting, supportive, and nurturing (Hutchinson \& Janiszewski Goodin, 2013; Mills et al., 2020; Wolf et al., 2015). A concept analysis of caring in nursing education (Salehian et al., 2017) suggested that caring involves faculty interest in knowing and responding to student needs, as well as their being flexible in suspending entrenched patterns of teaching. In addition to reducing student anxiety, the consequences of caring may include enhanced student empowerment, self-esteem, peace, and selfconfidence (Salehian et al., 2017). Validating student stress and endeavouring to mitigate some of that stress through double time might contribute to students feeling cared for by faculty and ultimately more engaged in their education. References to students' interpretation of double time in relation to faculty intent were interspersed with data reflective of the key themes of calming and enabling in this study, albeit not to the extent of constituting an additional theme:

Another side of the story is that it made me feel that my success means a lot to whoever came up with this initiative.

I think the double time during major exams is super helpful and amazing ... It is working perfectly. Thanks for thinking of us students.

Finally, pragmatically thinking, what difference might double time make to students' future practice upon graduation? Many intersecting stressors are associated with nursing as a profession, so many that some might argue the value of nursing student stress in preparing students to cope with the reality and stressors of their future practice. Indeed, some sources of stress may lead to eustress, a level of stress that might enhance nursing student performance (Gibbons, 2010). However, we were unable to find any published evidence that confirms students' ability to effectively manage the stress associated with written tests leads to improved ability to manage practice stressors upon graduation. In contrast, Rudman and Gustavsson (2012) proposed the 
opposite: study burnout (or academic stress) would lead to negative health, life, and occupational outcomes. The findings of their longitudinal study linked study burnout during nursing education to lower mastery of occupational tasks, less research utilization in everyday clinical practice, and higher turnover intentions at 1 year follow up post-graduation. Double time might help minimize the academic stress that negatively impacts graduates' effective transition to practice.

\section{Implications for Research and Education}

Our findings suggest that offering universal double time for all in-person major written tests/exams contributes to a calming and enabling student test experience, with minimal influence on student grades. From a pragmatic perspective, this experience might provide the healthful, caring, and empowering learning experience students need to fully engage in and learn from their nursing education. Furthermore, such learning experiences may have an impact extending beyond graduation, supporting new nurses to transition more effectively to the stressful world of practice.

These propositions, however, are only speculative at this point as there is a lack of any comparable research exploring the potential value of double time on written tests in nursing education. Future research could provide a fuller and more inclusive representation of double time efforts by involving the perspective of faculty, administration, and student services partners in a robust manner. Structuring such empirical work in the format of longitudinal investigation could also create links between what we do in nursing education and how graduates cope with the transition to nursing practice. Finally, expanding analyses within future studies to explore double time test impact in relation to level of student or type of test (i.e., nursing versus health science) might point to where and when to introduce double time to optimize its value-added for student success, both within and beyond the academy.

\section{Limitations}

The study was conducted in one large Canadian postsecondary institution, drawing on a sample of nursing students within one collaborative BN program during one academic year. There may be unique aspects of the organization or the program that influenced participants' perspectives. The cross-sectional nature of data collection limited the ability to compare the experience of double time as students progress through their nursing education. Analysis of data in aggregate form limited the ability to compare the experience of double time within different pathways common to nursing education. Finally, despite the good response rate to the study survey, we cannot be sure of the perspectives of those who did not respond.

\section{Conclusions}

This study challenged norms related to timed written in-person tests/exams and how the factor of time might be contributing to modifiable nursing student stress. In the absence of strong empirical guidance in the literature, we drew on the perspectives of several students regarding how written tests impact their learning experiences to determine variables of interest: time and grades. We could not affirm that time is the only barrier to effective student performance on written tests (i.e., grades). Extra time did not appear to compensate for students' lack of knowledge or competence when writing a test. However, we did reveal the healthful student experiences that might evolve when time limits for tests are relaxed. Double time has the potential to contribute to improved student mental health, more effective learning environments, and enhanced student preparedness for future practice. Pragmatically speaking, these consequences of double time might be worth its continuation. It might lead to graduates entering nursing more energized and 
Quality Advancement in Nursing Education - Avancées en formation infirmière, Vol. 8, Iss. 1 [2022], Art. 8

optimistic, rather than burned out from aspects of their educational experience and ill-prepared to take on the challenges of their new role. 


\section{References}

Beggs, C., Shields, D., \& Janiszewski Goodwin, H. (2011). Using guided reflection to reduce test anxiety in nursing students. Journal of Holistic Nursing, 29(2), 140-147. https://doi.org/10/1177/0898010110393352

Belnavis, C. S. (2019). Addressing students stress levels in nursing education programs [Senior honors thesis, State University of New York]. SUNY Open Access Repository. http://hdl.handle.net/20.500.12648/6744

Bonaccio, S., \& Reeve, C. L. (2010). The nature and relative importance of students' perceptions of the sources of test anxiety. Learning and Individual Differences, 20(6), 617-625. https://doi.org/10.1016/j.lindif.2010.09.007

Brodersen, L. D. (2017). Interventions for test anxiety in undergraduate nursing students: An integrative review. Nursing Education Perspectives, 38(3), 131-137. https://doi.org/10.1097/01.NEP.0000000000000142

Canadian Institutes of Health Research, Natural Sciences and Engineering Research Council of Canada, and Social Sciences and Humanities Research Council of Canada. (2014). TriCouncil Policy Statement: Ethical Conduct for Research Involving Humans. https://ethics.gc.ca/eng/documents/TCPS_2-2014_FINAL_Web.pdf

Chernomas, W. M., \& Shapiro, C. (2013). Stress, depression, and anxiety among undergraduate nursing students. International Journal of Nursing Education Scholarship, 10(1), 255266. https://doi.org/10.1515/ijnes-2012-0032

Duff, E. (2016). The effects of empowerment on role competency and patient safety competency for newly graduate nurse practitioners (Publication No. 4091) [Doctoral dissertation, University of Western Ontario]. Western Graduate and Postdoctoral Studies Electronic Thesis and Dissertation Repository. https://ir.lib.uwo.ca/etd/4091

Edelman, M., \& Ficorelli, C. (2005). A measure of success: Nursing students and test anxiety. Journal for Nurses in Staff Development, 21(2), 55-59.

Gibbons, C. (2010). Stress, coping and burn-out in nursing students. International Journal of Nursing Studies, 47(10), 1299-1309. https://doi.org/10.1016/j.ijnurstu.2010.02.015

Gibson, H. A. (2014). A conceptual view of test anxiety. Nursing Forum, 49(4), 267-277. https://doi.org/ 10.1111/nuf.12069

He, F. X., Turnbull, B., Kirshbaum, M. N., Phillips, B., \& Klainin-Yobas, P. (2018). Assessing stress, protective factors and psychological well-being among undergraduate nursing students. Nurse Education Today, 68, 4-12. https://doi.org/ 10.1016/j.nedt.2018.05.013

Hutchinson, T. L., \& Janiszewski Goodin, H. (2013). Nursing student anxiety as a context for teaching/learning. Journal of Holistic Nursing, 31(1), 19-24. https://doi.org/10.1177/0898010112462067

Khalaila, R. (2015). The relationship between academic self-concept, intrinsic motivation, test anxiety, and academic achievement among nursing students: Mediating and moderating effects. Nurse Education Today, 35(3), 432-438. https://doi.org/10.1016/j.nedt.2014.11.001 
Kinsella, E. A., Smith, K., Bhanji, S., Shepley, R., Modor, A., \& Bertrim, A. (2020). Mindfulness in allied health and social care professional education: A scoping review. Disability and Rehabilitation, 42(2), 283-295. https://doi.org/10.1080/09638288.2018.1496150

Labrague, L. J., McEnroe-Petitte, D. M., Gloe, D., Thomas, L., Papathanasiou, I. V., Edet, O. B., Tsaras, K., Leocadio, M. C., Colet, P., Kleisiaris, C. F., Fradelos, C., Rosales, R. A., Santos-Lucas, K. V., \& Velacaria, P. I. T. (2018). A literature review on stress and coping strategies in nursing students. Journal of Mental Health, 26(5), 471-480. https://doi.org/10.1080/09638237.2016.1244721

Labrague, L. J., McEnroe-Petitte, D. M., Papathanasiou, I. V., \& Tsaras, K. (2017). Stress and coping strategies among nursing students: An international study. Journal of Mental Health, 27(5), 402-408. https://doi.org/ 10.1080/09638237.2017.1417552

Lethbridge, K. L. (2010). Baccalaureate nursing students' perceptions of empowerment and reflective thinking over time [Doctoral dissertation, Publication No. NR73362]. ProQuest Dissertations and Theses Global.

McCarthy, B., Trace, A., O’Donovan, M., Brady-Nevin, C., Murphy, M., O’Shea, M., \& O'Regan, P. (2018). Nursing and midwifery students' stress and coping during their undergraduate education programmes: An integrative review. Nursing Education Today, 61, 197-209. https://doi.org/10.1016/j.nedt.2017.11.029

Mills, A., Ryden, J., \& Knight, A. (2020). Juggling to find balance: Hearing the voices of undergraduate nursing student nurses. British Journal of Nursing, 29(15), 897-903. https://doi.org/10.12968/bjon.2020.29.15.897

Moore, S. C., \& Ward, K. S. (2017). Nursing student perceptions of structural empowerment. Nursing Education Perspectives, 38(1), 32-33. https://doi.org/10.1097/01.NEP.0000000000000096

Myrick, F., \& Pepin, J. (2019). The upsurge in student anxiety and mental health challenges in today's postsecondary climate. Quality Advancement in Nursing Education, 5(1), 1-4. https://doi.org/10.17483/2368-6669.1210

Parsons, S. D., \& Teel, V. (2013). Double testing: A student perspective. Nursing Education Perspective, 34(2), 127-128. https://doi.org/ 10.5480/1536-5026-34.2.127

Pascoe, M. C., Hetrick, S. E., \& Parker, A. G. (2020). The impact of stress on students in secondary school and higher education. International Journal of Adolescence and Youth, 25(1), 104-112. https://doi.org/10.1080/02673843.2019.1596823

Prato, C. A., \& Yucha, C. B. (2013). Biofeedback-assisted relaxation training to decrease test anxiety in nursing students. Nursing Education Perspectives, 34(2), 76-81. https://doi.org/10.5480/1536-5026-34.2.76

Pulido-Martos, M., Augusto-Landa, J. M., \& Lopez-Zafra, E. (2012). Sources of stress in nursing students: A systematic review of quantitative studies. International Nursing Review, 59, 15-25. https://doi.org/10.1111/j.1466-7657.2011.00939.x 
Quinn, B. L., \& Peters, A. (2017). Strategies to reduce nursing student test anxiety: A literature review. Journal of Nursing Education, 56(3), 145-151. https://doi.org/10.3928/01484834-20170222-05

Rudman, A., \& Gustavsson, J. P. (2012). Burnout during nursing education predicts lower occupational preparedness and future clinical performance: A longitudinal study. International Journal of Nursing Studies, 49(8), 988-1001. https://doi.org/10.1016/j.ijnurstu.2012.03.010

Salehian, M., Heydari, A., Aghebati, N., \& Moonaghi, H. K. (2017). Faculty-student caring interaction in nursing education: An integrative review. Journal of Caring Sciences, 6(3), 257-267. https://doi.org/10.15171/jcs.2017.025

Schwartz, S. M., Evans, C., \& Agur, A. M. R. (2015). Comparison of physical therapy anatomy performance and anxiety scores in times and untimed practical tests. Anatomical Sciences Education, 8(6), 518-524. https://doi.org/10.1002/ase.1508

Shapiro, A. L. (2014). Test anxiety among nursing students: A systematic review. Teaching and Learning in Nursing, 9(4), 193-202. https://doi.org/ 10.1016/j.teln.2014.06.001

Siu, H. M., Laschinger, H. K., \& Vingilis, E. (2005). The effect of problem-based learning on nursing students' perceptions of empowerment. Journal of Nursing Education, 44(10), 459-469. https://doi.org/10.3928/01484834-20051001-04

Turner, K., \& McCarthy, V. L. (2017). Stress and anxiety among nursing students: A review of intervention strategies in literature between 2009 and 2015. Nursing Education in Practice, 22, 21-29. https://doi.org/ 10.1016/j.nepr.2016.11.002

Warms, C. A., \& Schroeder, C. A. (1999). Bridging the gulf between science and action: The "new fuzzies" of neopragmatism. Advances in Nursing Science, 22(2), 1-10. https://doi.org/10.1097/00012272-199912000-00002

Wolf, L., Stidham, A. W., \& Ross, R. (2015). Predictors of stress and coping strategies of US accelerated vs. generic baccalaureate nursing students: An embedded mixed methods study. Nurse Education Today, 35(1), 201-205. https://doi.org/10.1016/j.nedt.2014.07.005

Zhang, G., Fenderson, B. A., Schmidt, R. R., \& Veloski, J. J. (2013). Equivalence of students' scores on timed and untimed anatomy practical examinations. Anatomical Sciences Education, 6(5), 281-285. https://doi.org/10.1002/ase.1357

Zuriff, G. E. (2000). Extra examination time for students with learning disabilities: An examination of the maximum potential thesis. Applied Measurement in Education, 13(1), 99-117. https://doi.org/10.1207/s15324818ame1301_5 